\title{
PHYSICAL WORK CAPACITY AND PHYSICAL CONDITIONING IN PARAPLEGIC PATIENTS
}

\author{
By Evert Knutsson, M.D., Elizabeth Lewenhaupt-Olsson and Marika Thorsen \\ Department of Clinical Physiology, Karolinska Sjukhuset, \\ I040I Stockholm 60, Sweden
}

\section{INTRODUCTION}

Patients with spinal cord injuries often become excessively fatigued by even quite limited physical activity. This is of great disadvantage during the rehabilitation period since, in order to transfer, the patient relies mainly on the upper limbs for lifting, balancing and weight support. In our experience, some patients, due to a low tolerance to physical effort, find difficulty in learning to master their movements, and thus cannot benefit effectively from the prolonged and repeated periods of training necessary for optimal rehabilitation. This difficulty may be due to a deficient circulatory adaptation influencing performance in non-paretic parts of the body. Loss of supraspinal cardiovascular control at levels below the spinal cord injury may be causative, but the physical inactivity consequent to extensive motor paresis probably has its importance.

To find how the capacity of physical activity, which involves circulatory strain, is affected in patients with chronic spinal cord transections, maximal dynamic arm work performance, total amount of haemoglobin and blood volume were determined, since they are known to be altered by inactivity (cf. Sjöstrand, 1967). As will be shown, these are usually low compared with those of healthy individuals. The question then arises as to whether work capacity may be improved by training, despite the fact that this must be restricted to the relatively small muscle groups of the upper extremities. Thus, interval training was instituted and its effects on performance and blood volume were determined. The results obtained, emphasised the importance of assessing circulatory function in paraplegic subjects during their rehabilitation, and the value of physical conditioning when an optimal adjustment of the handicap is difficult to attain, due to a low physical fitness level.

\section{PATIENTS AND METHODS}

Twenty patients ( 15 men and five women) with spinal cord lesions at a level between $\mathrm{C}_{5}$ and $\mathrm{L}_{\mathrm{I}}$ (most distal uninvolved segment) were studied. A clinically complete chronic transection was present in 18 of the subjects. In the other two, the pareses below the level of injury were extensive. They were admitted to the Department of Neurological Rehabilitation of Karolinska Sjukhuset during the testing and training periods.

The total amount of haemoglobin and the blood volume were determined by the alveolar CO method (Sjöstrand, I948; Holmgren \& Ekelund, 1967). The physical work capacity was estimated by bicycle ergometer tests according to Sjöstrand (1960), the electrodynamically braked ergometer being adapted for arm work performance in the sitting position (fig. I, A). The tests always began with work at an intensity estimated to be low for the individual subject. In the 
weakest subjects, the initial load was five watts which was the lowest possible with the ergometer used. In the other patients, the initial load chosen was I6, 24 or 33 watts depending upon the estimated level of physical fitness. The initial load was
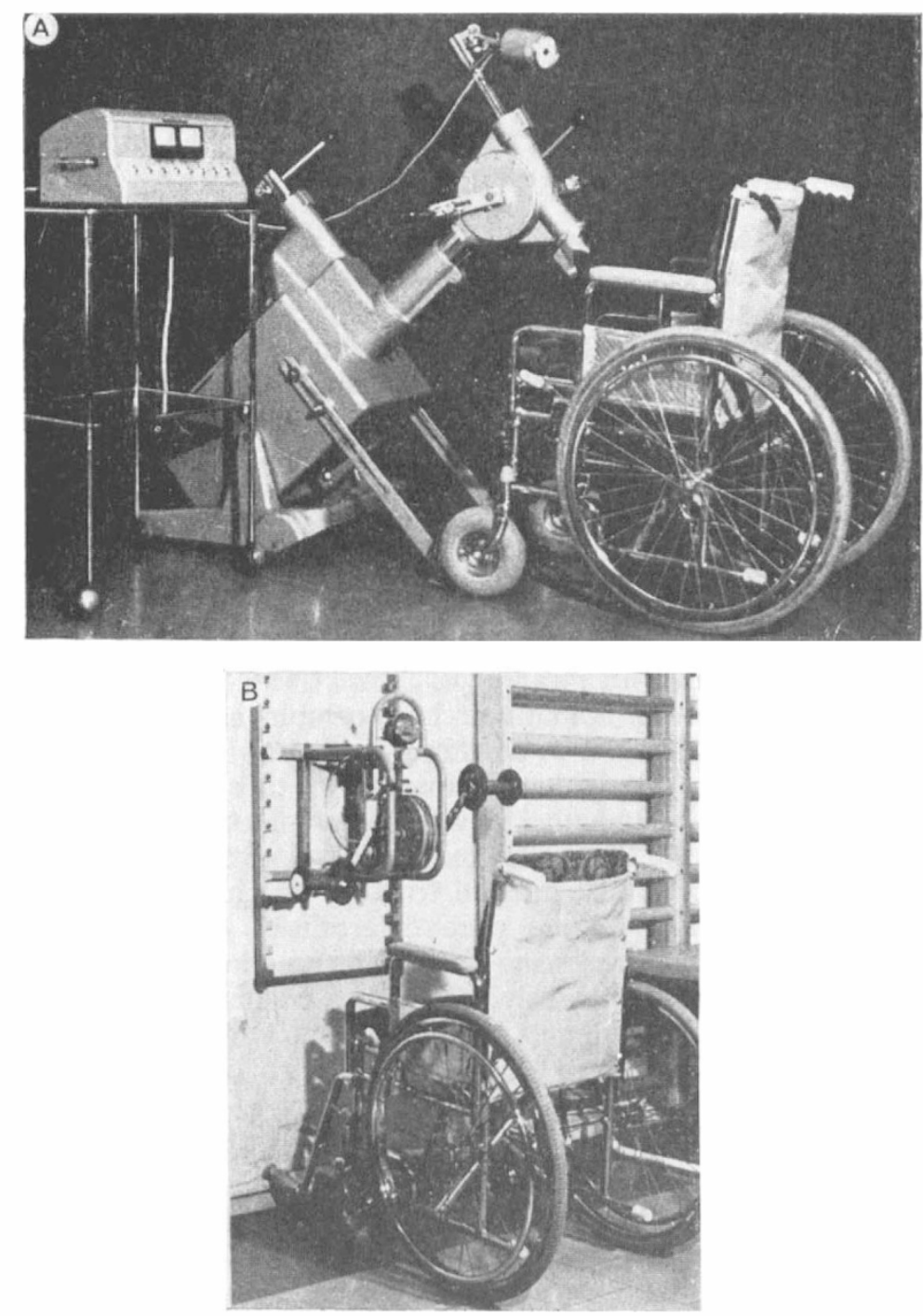

FIG. I

Ergometers for arm work performance. In $\mathrm{A}$ is shown the electrodynamically braked ergometer used for testing work performance. It is a conventional bicycle ergometer that has been tilted so that the pedal mechanism can be operated by using the arms while sitting, the pedals having been replaced by handles. B shows an ergometer specially designed for arm exercise. It has a mechanical brake and a maximum load of about I50 watts. The ergometer is fixed to a wall at a height convenient for operation from a wheelchair. 
maintained for six minutes after which the load was increased to a new level, I I to 33 watts higher, and maintained for six minutes before another step increase was made. The work test was continued until the heart rate approached I 70 beats/ minute unless fatigue made it necessary to discontinue the test before this heart rate was reached. Before, during and after the work period, precordial ECG, heart rate and blood pressure were taken, and the test discontinued if untoward reactions occurred. In three subjects, the work test was thus discontinued, due to an excessive fall in blood pressure (one case), pathological changes in ECG indicating a heart affection inapparent at rest (one case), and to back pain at the level of injury (one case).

Training was instituted in Io of the patients. They all had clinically complete cord transections at levels between $\mathrm{C}_{5}$ and $\mathrm{L}_{\mathrm{I}}$. During six consecutive weeks, the training took place 4-5 days each week. The exercises were made under continuous observation which included regular checks on heart rate and blood pressure. During the first few training sessions an exercise programme was determined for each patient. The aim of the programme was to induce circulatory strain as indicated by a marked increase in heart rate. It was found that the type of exercise was critical since muscle fatigue usually developed before any significant heart rate increase was attained. By using exercises of relatively low resistance performed at a high speed, a heart rate of $\mathrm{I} 4 \mathrm{O}-\mathrm{I} 8 \mathrm{O}$ beats/minute could be reached in a two minute exercise period in eight of the patients. In the other two, the highest heart rate ever reached was I IO and I 30 beats/minute, respectively.

In our experience, significant heart rate responses could usually be attained by certain arm exercises (double arm circling, boxing-like movements in different directions and diagonal double arm patterns, all with I-2 kg. hand weights), pulley resisted arm movements and exercise on a specially designed arm ergometer (fig. I, B; Odéen, I972). The arm and pulley exercises were performed with the patient attached to a tilt table by means of straps around the knees, hips and thorax. The fixation permitted resisted exercises of the upper extremities without risking loss of trunk balance in a head-up tilted position of approximately $80^{\circ}$.

Each training session consisted of alternate work and rest periods. The work periods were about two minutes long and the rest periods were 2-4 minutes. The first as well as the last work period were of low intensity. The intervening work periods were progressively increased in intensity, the third to the fifth usually driving the heart rate up to $140-180$ beats/minute.

\section{RESULTS}

Total Haemoglobin and Blood Volume. The total amount of haemoglobin (THb) varied between 428 and $879 \mathrm{~g}$. in the male patients, and between $3 \mathrm{II}$ and $438 \mathrm{~g}$. in the female patients. The amounts correspond to an average of $9.46 \pm \mathrm{I} \cdot 63$ (S.D., $n=\mathrm{I} 3$ ) g./kg. body weight in the men and of $7 \cdot 57 \pm \mathrm{I} \cdot 47$ $(n=4) \mathrm{g} . / \mathrm{kg}$. body weight in the women. Mean values and dispersions for healthy men and women at this clinic are I0.23 $\pm \mathrm{I} \cdot \mathrm{I} 8(n=\mathrm{I} 9 \mathrm{I})$ and $8.07 \pm 0.86$ $(n=56) \mathrm{g} . / \mathrm{kg}$. body weight, respectively. Thus, THb in the male patients was significantly decreased $(\mathrm{P}<0.05)$ as compared with healthy men. For an accurate assessment of deviations of THb it is of advantage to relate THb both to body weight and body length. The expected $\mathrm{THb}$ in each individual was thus calculated from the following regression equations: 


$$
\begin{aligned}
& \mathrm{THb}_{\text {men }}=6 \cdot 36 l+7 \cdot 27 w-93 \mathrm{I}, \\
& \mathrm{THb}_{\text {women }}=2 \cdot 95 l+6 \cdot 34 w-396 .
\end{aligned}
$$

In these, $l$ is body length in $\mathrm{cm}$. and $w$ is body weight in $\mathrm{kg}$. The optimal constants were determined by Ekelund (1973) from findings in healthy subjects (I9I men and 56 women), standard deviations of THb being 69.7 and $25.7 \mathrm{~g}$. in the correlations for men and women, respectively. Figure 2 gives expected against observed $\mathrm{THb}$ in male (A) and female (B) patients. As shown by the figures, six male and two female patients had a lower THb than anticipated from their length and body weight.

The blood volume varied between 3.9 and 6.6 litres in the male patients. Average volume was $5.15 \pm 0.82$ litres as compared to $6.05 \pm 0.82$ litres in healthy

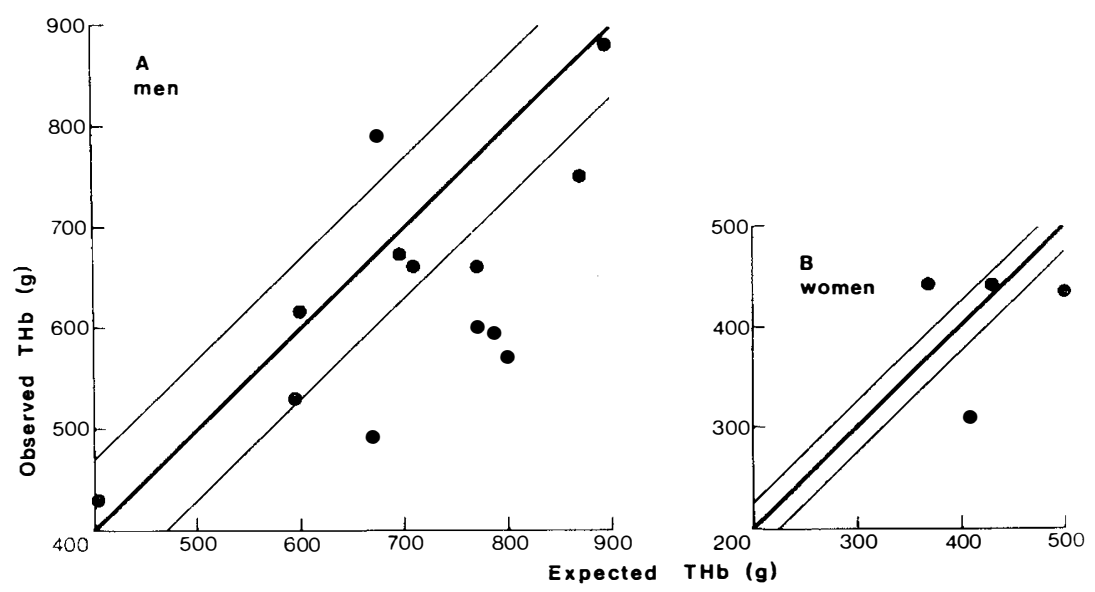

FIG. 2

Observed $\mathrm{THb}$ in $\mathrm{I} 3$ male (A) and four female (B) patients with chronic spinal cord injury given against $\mathrm{THb}$ as expected from individual body weight and length. Heavy lines indicate exact correspondence and thin lines give the range of 2 S.D. determined from measures in I9I healthy men (A) and 56 women (B).

men. In the female patients the average volume was 3.68 (range $3 \cdot 0-4 \cdot 2$ ) litres as compared to $4.39 \pm 0.6 \mathrm{I}$ litres in healthy women. In figure 3 the observed blood volumes are given against the expected blood volume (BV) as calculated from the following multiple regression correlations:

$$
\begin{array}{ll}
\mathrm{BV}_{\text {men }} & =0.055 \mathrm{I} l+0.0437 w-7.12, \\
\mathrm{BV}_{\text {women }} & =0.0237 l+0.0455 w-2.25,
\end{array}
$$

determined from the same normal material as the THb correlations, and having dispersions of 0.50 and 0.19 litres, respectively. As seen from the figures, the blood volume in II of the I7 patients was less than expected within the normal dispersion of 2 S.D.

Arm Work Capacity. Figure 4 gives heart rate during arm cycling in the I 4 men (A) and three women (B) whose work performance could be tested. Filled circles gives heart rate after six minutes of work at the load indicated. Open circles 
give heart rate after two minutes' work at a load too heavy to be managed for six minutes. Regression lines in $\mathrm{A}$ and $\mathrm{B}$ show heart rate to load relation during steady-state in healthy men and women respectively during arm work, thin lines
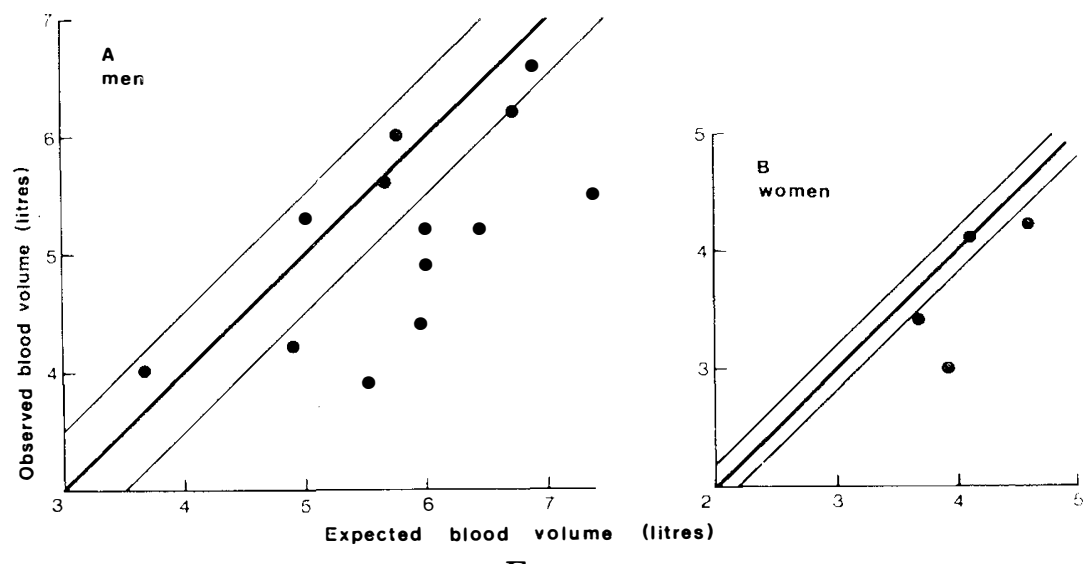

FIG. 3

Observed blood volumes in 13 male (A) and four female (B) patients with chronic spinal cord injury given against the blood volume expected from body weight and length. Lines indicate correspondence and 2 S.D. as in Figure I.
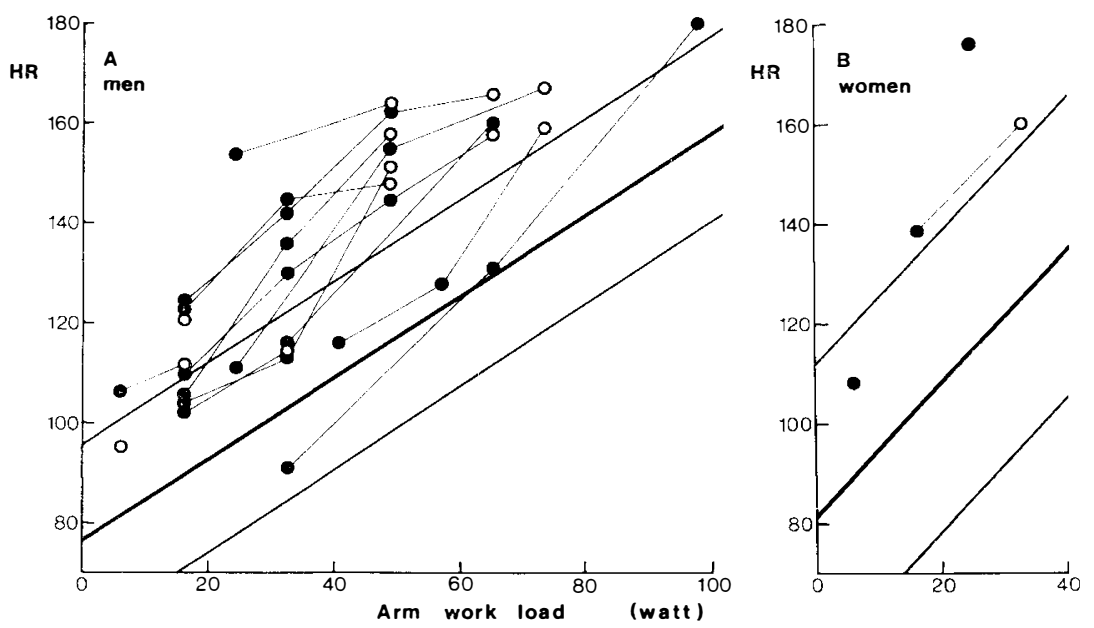

FIG. 4

Heart rate (beats/minute) during arm cycling at different loads in 17 patients with chronic spinal cord injury. Filled circles give heart rates after cycling for six minutes at the given loads. Unfilled circles give heart rates after cycling for two minutes at loads not possible to maintain for six minutes. Circles representing individuals are connected by thin lines. Heavy regression lines give the correlations (least squares) in healthy men (A) and women (B) between heart rate and load during arm cycling, and the range of 2 S.D. is indicated by thinner lines. 
indicating \pm I S.D. as determined by the method of least squares (Ekelund, I973). Physical work capacity in arm work at a heart rate equal to I 70 beats/minute (arm-PWC ${ }_{170}$ ) for healthy men is II4 watts; corresponding value for healthy women is 60 watts. Thus, in all the patients except one the maximal arm work performance was significantly lower than in healthy individuals.

In two of the men, those having the lowest work performance in figure $4, \mathrm{~A}$, pareses were present in the upper extremities. In one, the arm extensors and the pectoralis major muscles were weak. In the other, there was reduced strength in the shoulder muscles. In these two subjects the heart rate increase during the tests was restricted up to levels of 95 and II 2 beats/minute respectively. This restriction might be due to an inadequate degree of muscle work to induce sufficient strain on the circulation. However, since the cord injuries were at the $\mathrm{C}_{5}-6$ and $\mathrm{C}_{5}-\mathrm{T}_{4}$ levels respectively, and consequently the sympathetic outflow was partially or completely disrupted from supraspinal centres, a restriction of the sympathetic

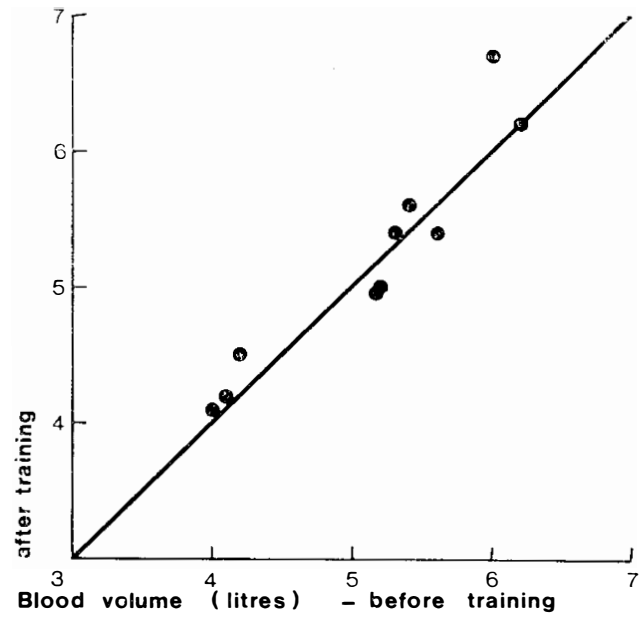

FIG. 5

Blood volume before and after training for six weeks in Io patients with complete, chronic spinal cord transections.

acceleratory effects on the heart must be considered. In the other I 5 patients, pareses of the upper extremities were not present, and in none of them were there any signs of cord injury above the $\mathrm{T}_{4}$ level. Consequently, the low arm work performance in this group cannot be ascribed either to motor pareses in the upper limbs or to any disturbance in autonomic control of cardiac functions.

Effects of Training. In the Io patients who participated in the six week interval training, the mean total amount of haemoglobin before the training was $583 \pm 125 \mathrm{~g}$. After training it was $60 \mathrm{I} \pm \mathrm{I} 25 \mathrm{~g}$. The mean paired difference was insignificant ( $19 \pm 29$ g.) The blood volumes before and after training are shown in Figure 5 . Mean volume before was $5 . \mathrm{I} \pm 0.9$ litres. After training it was slightly increased, but the mean difference was insignificant ( $0.1 \pm 0.2$ litres).

The arm work capacity before and after training is shown in figure 6. This capacity is expressed in arm-PWC ${ }_{170}$ (filled circles) in all except two cases in whom the heart rate increase was restricted. In one of these, the work capacity is given as arm-PWC ${ }_{150}$ (cross); in the other, it is given as maximal load managed 
during four minutes (unfilled circle). Fis seen in the figure, there was a marked increase in arm work performance in the majority of the subjects. The mean work performance before was $40 \cdot 2 \pm 27 \cdot 3$ watts; after it was $56 \cdot 5 \pm 30 \cdot 6$ watts. A paired $t$-test showed that the difference was significant $(\mathrm{P}<0.02)$. In the group of three patients without any change or decrease in work performance, two subjects had cervical cord injuries while the third patient had a cord transection at T6. In the remainder, the levels of injury were between $\mathrm{T}_{7}$ and $\mathrm{L}_{\mathrm{I}}$. These subjects had a mean increase in work performance of 50 per cent.

FIG. 6

Work capacity measured by arm cycling in the sitting posture in Io patients with complete chronic spinal cord transections. Capacity after training (six weeks) is given against initial capacity. Filled circles are work loads as extrapolated to a heart rate of $170 /$ minute. Cross is load at I50 beats/ minute. Open circle, load at exhaustion after cycling for four minutes.

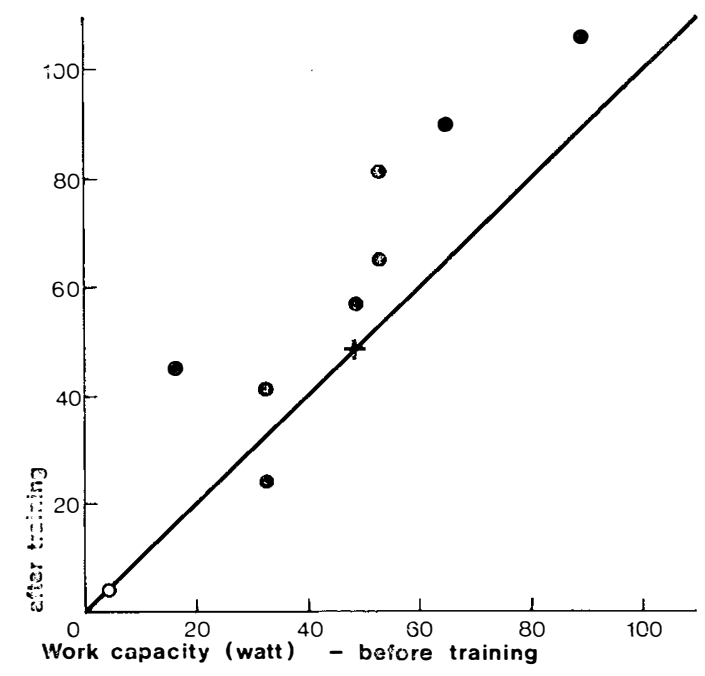

DISCUSSION

The results of the present study show that the arm work capacity in patients with chronic spinal cord injuries is frequently lower than that in healthy subjects. Low arm work performance in patients with transections at high spinal levels is to be expected from the motor pareses in the upper body parts. With a lower lesion, innervation to the upper extremities is unaffected, and the patients have usually become skilled in the compensatory use of the upper limbs in ambulary movements, and in some a relative hypertrophy in the arm and shoulder muscles develops. Yet, arm work capacity in the exercise test used was low. This may be explained by an adaptation of cardiovascular dimensions to the physical inactivity to which the patients are confined, due to pareses of the lower body parts with its large muscle groups. The decrease in the total amount of haemoglobin and in the blood volume found in the present study supports this assumption, since these are known to become adjusted to the demands set by the physical activity of the individual (Sjöstrand, 1953). Thus, in inactivated healthy subjects as well as in patients with a handicap or disease leading to relative physical inactivity, e.g. blindness (Sjöstrand, I967) and Fredrich's ataxi (Thorén, I964), THb and blood volume are low.

In patients with spinal cord transection, deficits in cardiovascular control may 
further limit work performance. Regulatory functions are increasingly deficient the higher the lesion of the spinal cord (Guttmann \& Whitteridge, I947). There are only minor disturbances in patients with lesions at or below T6. At lesions above this level, the commonly observed orthostatic reactions and autonomic hyperreflexia indicate deficient supraspinal control of major parts of the vascular bed (Guttmann, I946, I953; Guttmann \& Whitteridge, I947; Jonason, I947; Cunningham, Guttmann, Whitteridge \& Wyndham, I953). The distinct difference in severity of vasomotor disturbances at lesions above and below mid-thoracic level may be due to the loss of supraspinal control of the splancnic outflow in lesions above $\mathrm{T}_{4}-6$. Deprivation of influences on the splancnic outflow from circulatory centres will limit adaptations to circulatory strain in the splancnic vascular bed, the adrenals and the kidneys. The plasma cathecholeamine level will decrease, and its increase in response to head-up tilting is diminished (Robinson \& Munro, I958; Munro \& Robinson, I960; Robinson \& Smith I960; Imhof, Hediger \& Käser, I962, Guttmann, Munro, Robinson \& Walsh, I963). Plasma renin levels may, however, be high and tilting to upright posture will induce an elevation of the plasma renin concentration in spite of cord transection above the splancnic outflow (Johnson, Park \& Frankel, I97I; Mendelsohn \& Johnston, I97I). The release of renin has been suggested to explain the increased tolerance to vertical posture which paraplegic patients achieve with time (Guttmann, I946, 1954; Jonason, I947) and which can be observed after a series of repeated changes in posture between a horizontal and vertical position (Johnson, Smith \& Spalding, 1969).

The rapid adaptation observed by Johnson et al. (1969) is independent of any blood volume increase, and may consequently depend upon the vasoconstrictory effects of angiotensin, formed after renin release. From the present study showing that the blood volume in chronic paraplegia is frequently very low, it seems unlikely that the chronic vascular adaptation obtained with time and training is dependent upon a compensatory increase in blood volume to counterbalance the effects of sequestration of blood in the vascular beds.

In high spinal lesions, which deprive the uppermost part of the sympathetic outflow from supraspinal connections, the sympathetically mediated acceleratory effects upon the heart evoked by cardiovascular centres is abolished. In patients with complete cervical cord transections, the heart rate increase normally seen during voluntary contraction in a non-paretic muscle group is completely abolished by atropin block (Freyschuss \& Knutsson, 1969). This heart rate increase in response to effort to contract, appearing also in healthy subjects, is sustained after local neuromuscular block eliminating possible feed-back from the contracted muscles (Freyschuss, 1970). Thus, it must originate from supraspinal centres and be elicited by an inhibition of the vagal outflow to the heart. Consequently, it was suggested that the heart rate regulation in complete cervical cord transection is attained by varying the vagal tone. This would imply that the heart rate increase in these cases is restricted up to levels just above roo beats/minute.

In the patients with cervical lesions admitted to this study there was a significant restriction of the heart rate increase during the arm cycling. In one with complete transection at $\mathrm{C}_{5}-6$ the highest heart rate ever seen was I I o beats/minute which should be a frequency attainable by inhibition of vagal impulses (Freyschuss \& Knutsson, I969; Corbett, Frankel \& Harris, I97I). In the other the injury was partial between $\mathrm{C}_{5}$ and $\mathrm{T}_{3}$ and complete at $\mathrm{T}_{4}$. The maximal heart rate 
during his arm work varied between I IO and I30 beats/minute. Though the work load was very low due to some paresis in the upper limbs, the effort was $\mathrm{m}$ ximal. Thus, a larger increase of the heart rate was to be expected had the control of sympathetic outflow to the heart been adequate. Anomalous responses to head-up tilting with heart rates greatly exceeding that explained by only vagal inhibition are occasionally observed in tetraplegic patients (Corbett et al., I97I). Such responses suggest stimulation via cardiac beta-receptors in reflexes acting through the isolated spinal cord, and may depend upon the well-known autonomic hyperreflexia in patients with high spinal cord transections (Guttmann, I947; Pollock, et al., I95I; Cunningham et al., I953; Whitteridge, I954; Kurnick, I956; Cole, Kottke, Olson \& Stradal, I967). If, however, such unrestrained reactions are excluded then the heart rate changes in patients with complete cervical cord transections and seem to be restricted to those attained by alterations in vagal tone.

Work Performance after Training in Paraplegics. In response to physical conditioning with arm work, healthy subjects decrease their heart rate to load ratios (Clausen, Trap-Jensen \& Lassen, 1970). This effect is in part due to local changes in the exercised arm muscles, the central circulatory adaptations to exercise being relatively slight (Clausen, Klausen, Rassmussen \& Trap-Jensen, I97I). The relative effects on work performance in the paraplegic patients admitted to this study are much more pronounced than in healthy subjects. This is most likely due to the low initial physical fitness level consequent to the inactivity preceding the physical conditioning (cf. Grimby \& Saltin, I97I). In untrained subjects even low work intensities are sufficient to improve physical condition (Roskamm, I967; Siegel, Blomqvist \& Mitchell, 1970). Ekblom and Lundberg (1968), in a study of the effects of training with arm work in adolescents with severe motor handicaps, including patients with paraplegia due to myelomeningocele, found an increase of 40 per cent. in the arm work performance. This increase is of the same order of magnitude as the improvements observed in the present study. Thus, in spite of the fact that arm work in a healthy subject implies a relatively low degree of strain on the circulation, it seems to be adequate for conditioning in patients with a low physical fitness level.

In the patients with high spinal cord transections, however, no improvements were observed after the training. Whether this was due to the grave cardiovascular disturbances, or the inability to obtain sufficient strain on the circulation due to the motor pareses, cannot be decided.

Precautions during Conditioning Exercises in Paraplegic Patients. Experiences gained in the present study indicate that consideration should be given to some precautions not usually needed in other groups of patients and consequently not included in the commonly used guide lines for exercise tests and physical conditioning (Sjöstrand, I967; Cooper, I970). Thus, consideration has to be given to the possible effects of bladder reflexes, the need for skin care and the necessity of checking cardiac function, orthostatic reactions and blood pressure during exercise.

To minimise the effects on the circulation by the hyperactive bladder distension reflexes (cf. Guttmann \& Whitteridge, I947) the patients bladder is preferably emptied prior to exercise. Due to sensory loss there is a possibility of inducing pressure sores by the increased skin strain during exercise. Thus, care must be aken to unload the body supporting skin areas at regular intervals.

The paraplegic patient does not normally strain the circulation in daily 
activity. Free wheelchair driving, for instance, increases the heart rate on the average only up to 97 beats/minute (Stoboy, Rich \& Lee, 197I). Thus, myocardial insufficiency may be inapparent by clinical signs, as was the case in one of the patients admitted to this study (see Methods). Before conditioning training is instituted, electrocardiography with precordial leads taken during arm work with step-wise intensity increase, is recommended. Both during the exercise test and during several of the first training sessions, until the reactions to the strain of the exercise in the individual case is thoroughly known, the patient should be kept under constant observation. Orthostatic reactions are prone to occur in some patients, and they may occur quite unexpectedly and cause fainting if a horizontal body posture cannot be attained quickly. A tilt-table which allows rapid changes to the horizontal body posture is of great value.

Blood pressure fall during arm exercise may occur in patients showing no sign of orthostatic reactions when standing or in a sitting posture during rest. Such reactions were mentioned by Bidart, Durand and Martineaud (I97I) who suggested they were due to deficient vascular adaptation to exercise in the splancnic area in patients with transections above the T6 level. Measurements of aortic pressure by means of an indwelling catheter during arm work in patients with mid-thoracic transections (Freyschuss \& Knutsson, unpublished data) have revealed a fall of aortic pressure down to $73-75 \mathrm{~mm}$. Hg systolic and $36-39 \mathrm{~mm}$. $\mathrm{Hg}$ diastolic pressure within about I minute of arm work in a patient with transection at T4. Though this patient did not show any signs of orthostatic reaction while sitting during daily activities, he could not participate in conditioning training (see Methods). However, in two other patients with mid-thoracic lesions, the arterial pressure was kept at adequate levels during maximal loads of $65-73$ watts. Thus, in practice it is not possible to ascertain the responses to exercise from the level of injury.

\section{SUMMARY}

In a group of patients with chronic spinal cord injury at the $\mathrm{C}_{5}-\mathrm{LI}_{\mathrm{I}}$ level, the total amount of haemoglobin (THb), the blood volume and the arm work capacity were measured. In IO of the patients with clinically complete transections at $\mathrm{C}_{5}-\mathrm{L}_{1}$, the effects of conditioning exercises with the upper limbs were estimated.

$\mathrm{THb}$ in the male patients was $9 \cdot 46 \pm \mathrm{I} \cdot 63$ (mean, S.D., $n=\mathrm{I} 3$ ) g./kg. body weight which is less than normal $(P<0 \cdot 05)$. In the female patients it was $7 \cdot 57 \pm \mathbf{I} \cdot 47$ $(n=4)$ g. $/ \mathrm{kg}$. body weight. Eight patients had significantly lower THb than expected from their body weight and length.

The blood volume in male patients was $5.15 \pm 0.82(n=13)$ litres; in females, it was 3.68 (range $3 \cdot 0-4 \cdot 2, n=4$ ) litres. In I I of the I 7 patients the blood volume was significantly less than expected from the body weight and length.

The maximal arm work capacity, as estimated from an exercise test using arm cycling in the sitting posture, was low as compared with that of healthy individuals. In two patients with spinal injury at cervical levels, the heart rate increased to IOO-I 30 beats/minute during maximal effort. In the rest $\left(\mathrm{T}_{4}-\mathrm{L}_{\mathrm{I}}\right)$, heart rates of I45-I 80 beats/minute were reached.

After the training, four or five times a week for six weeks, THb and blood volumes were not changed significantly but the mean arm work performance (arm-PWC ${ }_{170},{ }_{150}$ or max.) increased from $40 \cdot 2 \pm 27 \cdot 3$ watts to $56 \cdot 5 \pm 30 \cdot 6$ watts, which is significant $(\mathrm{P}<0.02)$. There was no improvement in the three patients 
with lesions at $\mathrm{C}_{5}$-T6. All the others (T6-LI) increased their work performance; the mean increase was 50 per cent.

\section{RÉSUMÉ}

Chez un groupe de patients ayant une ancienne lésion médullaire de niveau lésionnel compris entre $\mathrm{C}_{5}$ et $\mathrm{L}_{1}$, on a mesuré la quantité totale de hémoglobine $(\mathrm{THb})$, le volume sanguin, et la capacité de travail physique des membres supérieurs. On a etudié les effets d'exercice physique avec les membres supérieurs chez Io patients avec lésions cliniquement complètes entre $\mathrm{C}_{5}$ et $\mathrm{L}_{\mathrm{I}}$.

Chez les patients masculins, THb était $9 \cdot 46 \pm \mathrm{r} \cdot 63$ (moyenne, écart-type, $n=\mathrm{I} 3$ ) g. $/ \mathrm{kg}$. poids du corps, inférieure à la valeur constatée chez le sujet normal $(\mathrm{P}<0.05)$. Chez les patients féminins $\mathrm{THb}$ était inférieur à la normale chez deux. Un total de 8 patients avaient une valeur $\mathrm{THb}$ qui était significativement inférieure à celle prévue selon leur poids et longuer du corps.

Le volume sanguin chez les patients masculins était $5 \cdot 15 \pm 0.82(n=13)$ litres et chez les patients féminins était $3.68(3 \cdot 0-4 \cdot 2)$ litres. Chez II des 17 patients le volume sanguin était significativement inférieur au volume prévu selon le poids et la longuer du corps.

La capacité maximum de travail physique des membres supérieurs calculée par un épreuve d'exercice utilisant un ergomètre adapté au membres supérieurs et dans la position assise, était basse, comparée à celle d'individus normaux. Deux patients avec lésions cérvicales, avaient une élévation du rythme cardiaque jusqu'a 100-130/minute pendant un effort maximum. Chez les autres patients $\left(\mathrm{T}_{4}-\mathrm{LI}\right)$, des rythmes cardiaques de I45-I80/ minute ont été atteint.

Après une periode d'exercice des membres supérieurs, 4-5 fois la semaine pendant 6 semaines, $\mathrm{THb}$ et le volume sanguin n'étaient pas significativement changés. La valeur moyenne de la capacité de travail physique des membres supérieurs a augmenté de $40 \cdot 2 \pm 27 \cdot 3$ watts à $56 \cdot 5 \pm 30 \cdot 6$ watts, une augmentation significative. Il n'y avait pas d'amélioration chez 3 patients avec lésions entre $\mathrm{C}_{5}-\mathrm{T} 6$. Tous les autres ( $\mathrm{T}_{7}-\mathrm{LI}_{\mathrm{I}}$ ) ont amélioré leur capacité de travail physique; la moyenne d'amélioration ètait de 50 pourcent.

\section{ZUSAMMENFASSUNG}

In einer Gruppe von Patienten mit chronischer Rückenmarkschädigung in einer Höhe von $\mathrm{C}_{5}$ bis $\mathrm{LI}_{1}$ wurden die Gesamtmenge von Hämoglobin $(\mathrm{THb})$, das Blutvolumen und die Arm-Arbeitsleistung gemessen. Bei Io Patienten mit klinisch komplettem Querschnitt von $\mathrm{C}_{5}$ bis $\mathrm{LI}_{\mathrm{I}}$ wurde der Effect von Konditionsübungen mit den oberen Extremitäten bewertet.

Der THb-Wert bei den männlichen Patienten lag mit $9 \cdot 46 \pm \mathrm{I} \cdot 63$ (Mittelwert, Standardabweichung, $n=$ 13) g. $/ \mathrm{kg}$. Körpergewicht niedriger als der Normalwert $(\mathrm{P}<0.05)$. Bei den weiblichen Patienten betrug der THb-Wert $7 \cdot 57 \pm \mathrm{I} \cdot 47(n=4)$ g./kg. Körpergewicht. 8 Patienten hatten niedrigere THb-Werte als nach Körpergewicht und Grö $\beta$ e zu erwarten war.

Die maximale Arm-Arbeitsleistung, gemessen während eines Übungstestes mit kreisförmigen Radfahrbewegungen des Arms im Sitzen, war im Vergleich zu gesunden Individuen gering. Bei 2 Patienten mit Rückenmarkschädigung im Halsbereich erhöhte sich die Herzfrequenz auf IOO-I 30 Schläge pro Minute bei maximaler Leistung. Bei den übrigen Patienten ( $\mathrm{T}_{4}-\mathrm{LI}$ ) wurden I 45-I80 Schläge/Minute erreicht.

Nach 6-wöchigem Training, 4-5 Mal pro Woche, änderten sich THb-Wert und Blutvolumen nicht signifikant. Die mittlere Arm-Leistungsfähigkeit (Arm-PWC I70, I 50 oder max.) erhöhte sich von $40 \cdot 2 \pm 27 \cdot 3 \mathrm{w}$ auf $56 \cdot 5 \pm 30 \cdot 6 \mathrm{w}$ signifikant $(\mathrm{P}<0 \cdot 02)$. Bei den 3 Patienten mit Läsionen in Höhe C5-T6 wurde keine Verbesserung beobachtet. Alle anderen Patienten $\left(\mathrm{T}_{7}-\mathrm{Lr}\right)$ konnten ihr Leistungsvermögen um durchschnittlich $50 \%$ steigern.

Acknowledgements. This study was supported by grants from the Swedish Medical Research Council, the Swedish Multiple Sclerosis Foundation and Karolinska institutets

$$
\text { I I } / 3-Q
$$


fonder. We wish to thank Dr. U. Lindblom for acting as our consultant and Professor T. Sjöstrand and Dr. U. Freyschuss for invaluable criticism and advice.

\section{REFERENCES}

Bidart, Y., Durand, J. \& Martineaud, J. P. (I97I). Path.-Biol. 19, I3.

Clausen, J. P., Klausen, K., Rassmussen, B. \& Trap-Jensen, J. (I97I). Acta physiol. scand. 82, 35A.

Clausen, J. P., Trap-Jensen, J. \& Lassen, N. A. (I970). Scand. F. clin. Lab. Invest. 26, 295.

Cole, T. M., Kottke, F. J., Olson, M. Stradal, L. \& Niederleh, B. S. (1967). Arch. Phys. Med. 48, 359.

Cooper, K. H. (1970). f. Am. Med. Ass. 211, I663.

Corbett, J. L., Frankel, H. L. \& Harris, P. J. (I97I). F. Physiol. 21 5, 4I I-43I.

Cunningham, D. J. C., Guttmann, L., Whitteridge, D. \& Wyndham, C. H. (1953). F. Physiol. I2I, 581.

Ekblom, B. \& Lundberg, A. (1968). Acta Pediat. Scand. 57, 7 I.

Ekelund, L.-G. (1973). Personal communication.

FREYSCHUSS, U. (1970). Acta physiol. scand. 78, Suppl. 342, I.

FREYSCHUSS, U. \& KNUTSSON, E. (1969). Life Sci. 8, $42 \mathrm{I}$.

Grimby, G. \& Saltin, B. (I97I). Scand. F. Rehab. Med. 3, 6.

Guttmann, L. (1946). Brit. F. Phys. Med. 9, I62.

GutTmanN, L. (1953). History of the Second World War. United Kingdom Medical Series, Vol. Surgery, p. 422.

Guttmann, L. (1954). In CIBA Foundation Symposium: Peripheral Circulation in Man (edited by G. Wolstenholme \& J. Freeman), p. I9I. London: Churchill.

Guttmann, L., Munro, A. F., Robinson, R. \& Walsh, J. (1963). Paraplegia, I, 4.

GutTMANN, L. \& WhitTERIDGe, D. (1947). Brain, 70, 36r.

Holmgren, A. \& Ekelund, L.-G. (I967). In Clinical Physiology. Pathophysiological Basis and Practical Application (edited by T. Sjöstrand), p. 24I. Stockholm: Svenska Bokförlaget.

ImhoF, P., Hedinger, F. \& Kaser, H. (I962). Helv. Med. Acta, 29, I83.

Johnson, R. H., PARK, D. M. \& Frankel, H. L. (I97I). Paraplegia, 9, I46.

Johnson, R. H., Smith, A. C. \& Spalding, J. M. K. (I969). Clin. Sci. 36, 77.

Jonason, P. H. A. (1947). Proc. Roy. Soc. Med. 40, I88.

KuRNICK, N. B. (I956). Ann. intern. Med. 44, 678.

Mendelsohn, F. A. \& Johnston, C. I. (I97I). Aust. N. Z. F. Med. 4, 393.

Munro, A. F. \& Robinson, R. (I960). F. Physiol. I 54, 244.

OdÉEN, I. (1972). Training of Physical Work Capacity in Wheel-chair Patients, p. I. Sweden: Rehabförlaget, Sollentuna.

Pollock, L. J., Boshes, B., Chor, H., Finkelman, I., Arieff, A. J. \& Brown, M. (I95I). f. Neurophysiol. I4, 85 .

Robinson, R. \& MunRo, A. F. (I958). Nature, I 82, 805.

Robinson, R. \& Smith, P. (I960). Nature, I 86, 240.

Roskamm, H. (1967). Canad. Med. Ass. F. 22, 895.

Siegel, W., Blompvist, G. \& Mitchell, J. H. (I970). Circulation, 4I, I9.

SJöstrand, T. (1948). Acta physiol. scand. I6, 2 I I.

Sjöstrand, T. (I953). Physiol. Rev. 33, 202.

Sjöstrand, T. (1960). Clinical Cardiopulmonary Physiology, p. 20I. New York: Grune \& Stratton.

Sjöstrand, T. (1967). Clinical Physiology. Pathophysiological Basis and Practical Application (edited by T. Sjöstrand), pp. 3 and 529. Stockholm: Svenska Bokförlaget.

Stoboy, H., Rich, B. W. \& LeE, M. (I97I). Paraplegia, 8, 223.

Thoren, C. (1964). Acta pediatrica, 53, Suppl. 153, 56.

WhitTERIDGE, D. (1954). Edinburgh Med. F. 61, I. 